\title{
Production of the Neurotoxin BMAA by a Marine Cyanobacterium
}

\author{
Sandra Anne Banack ${ }^{1,2}$, Holly E. Johnson ${ }^{1}$, Ran Cheng ${ }^{1}$ and Paul Alan Cox ${ }^{1, *}$ \\ ${ }^{1}$ Institute for Ethnomedicine, Box 3464, Jackson Hole, Wyoming 83001, USA; E-mails: \\ sbanack@fullerton.edu (Sandra Anne Banack); holly@ethnomedicine.org (Holly E. Johnson); \\ ladianaus@hotmail.com (Ran Cheng) \\ ${ }^{2}$ Department of Biological Science, California State University, Fullerton, California 92834, USA \\ * Author to whom correspondence should be addressed; E-mail: paul@ethnomedicine.org
}

Received: November 17, 2007 / Accepted: 4 December 2007 / Published: 6 December 2007

\begin{abstract}
Diverse species of cyanobacteria have recently been discovered to produce the neurotoxic non-protein amino acid $\beta$-methylamino- $L$-alanine (BMAA). In Guam, BMAA has been studied as a possible environmental toxin in the diets of indigenous Chamorro people known to have high levels of Amyotrophic Lateral Sclerosis/ Parkinsonism Dementia Complex (ALS/PDC). BMAA has been found to accumulate in brain tissues of patients with progressive neurodegenerative illness in North America. In Guam, BMAA was found to be produced by endosymbiotic cyanobacteria of the genus Nostoc which live in specialized cycad roots. We here report detection of BMAA in laboratory cultures of a free-living marine species of Nostoc. We successfully detected BMAA in this marine species of Nostoc with five different methods: HPLC-FD, UPLC-UV, Amino Acid Analyzer, LC/MS, and Triple Quadrupole LC/MS/MS. This consensus of five different analytical methods unequivocally demonstrates the presence of BMAA in this marine cyanobacterium. Since protein-associated BMAA can accumulate in increasing levels within food chains, it is possible that biomagnification of BMAA could occur in marine ecosystems similar to the biomagnification of BMAA in terrestrial ecosystems. Production of BMAA by marine cyanobacteria may represent another route of human exposure to BMAA. Since BMAA at low concentrations causes the death of motor neurons, low levels of BMAA exposure may trigger motor neuron disease in genetically vulnerable individuals.
\end{abstract}

Keywords: Nostoc, motor neuron disease, ALS/PDC, LC/MS/MS, biomagnification 


\section{Introduction}

Cyanobacteria produce a variety of toxic compounds known as cyanotoxins [1]. Human health consequences of cyanotoxins have been of increasing concern as the impacts of cyanobacterial blooms in water supplies as well as near-shore marine ecosystems have become better understood [2]. Poisonings from cyanobacterial blooms can be catastrophic [3], such as the death of 50 dialysis patients following exposure to inadequately treated water from the Tabocas Reservoir in Brazil or the hospitalization of 140 children and 10 adults who drank cyanobacterially-contaminated water impounded by the Solomon dam in Australia [4, 5]. Cyanobacterial toxins have also been implicated in wildlife deaths in fisheries and terrestrial mammals, and can accumulate within the ecosystem. Potent hepatotoxins such as cyclic heptapeptides including microcystins, and cyclic pentapeptides including nodularins are produced by Anabaena, Microcystis, Oscillatoria, Nostoc, Anabaenopsis, and Nodularia species. Different neurotoxins are known to be produced by cyanobacteria including anatoxin-a, homoanatoxin-a, anatoxin-a(S), and saxitoxins from Anabaena, Aphanizomenon, Oscillatoria, Lyngbya, and Cylindrospermopsis [1,3].

We found that endophytic cyanobacteria of the genus Nostoc resident in specialized roots of the Guam cycad Cycas micronesica Hill (Cycadaceae) produced a different neurotoxin, $\beta$-methylamino- $L$ alanine (BMAA), which is found throughout cycad tissues $[8,9]$. This led to a broader examination of BMAA production by other taxa of cyanobacteria, including 30 laboratory strains of free-living cyanobacteria, representing five major microbiological taxonomic groups of Rippka et al. [10]. Of the thirty laboratory cultures, 29 had free or protein-bound BMAA, as did a sample of an ocean Trichodesmium bloom [11]. BMAA has also been found in bloom samples of cyanobacteriallycontaminated water supplies in the United Kingdom, where it was found to co-occur with other cyanotoxins including microcystins, nodularin, anatoxin-a, and saxitoxins [12].

The co-occurrence of BMAA with other cyanotoxins may be of ecological importance, since BMAA can potentiate injury to motor neurons at concentrations as low as $10 \mu \mathrm{M}$ [13]. Alone, BMAA has been found to selectively kill motor neurons at concentrations as low as $30 \mu \mathrm{M}$ by AMPA/kainate receptor activation [14].

Figure 1. BMAA.

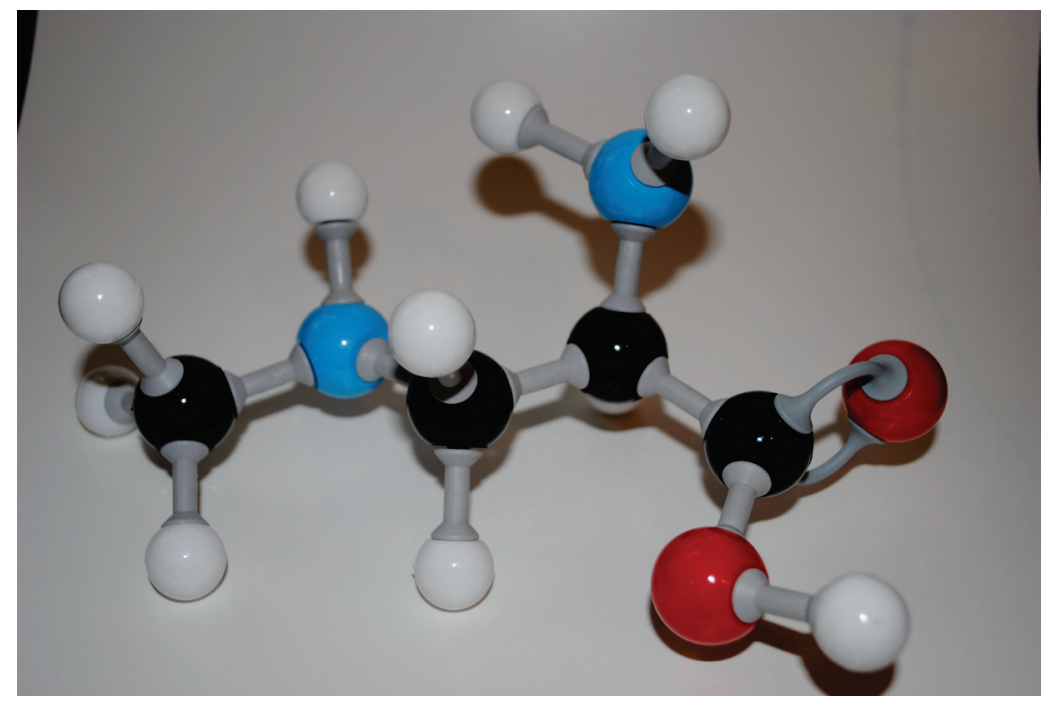


Although BMAA is a glutamate agonist at AMPA and NMDA receptors, it is a structurally dissimilar polar amino acid with two functional groups. Also known by the synonyms $\alpha$-amino- $\beta$ methylaminopropionic acid (MeDAP) and $\mathrm{S}(+)-m$-methyl- $\alpha, \beta$-diaminopropionic acid, BMAA has a molecular weight of 118.13 . Originally isolated from the seeds of cycads, BMAA can be synthesized from $\alpha$-acetamidoacrylic acid [15, 16]. Its structure is basically that of alanine with an added methylated amino group (Figure 1). Historically, BMAA was thought to be a possible slow toxin [17] associated with neurodegenerative illness among the Chamorro people of Guam [18]. The interest in BMAA has recently been renewed with evidence that BMAA is incorporated into the protein fraction of cyanobacteria, cycads, animals that forage on cycad seeds, as well as indigenous people with traditional diets rich in BMAA $[8,19]$. The incorporation and storage of BMAA in protein explains not only how biomagnification of a water-soluble molecule can occur, but also may account for the observed disease latency in ALS/PDC due to the intermittent release of the endogenous neurotoxic reservoir stored in the proteins [19]. Some forms of progressive neurodegenerative illness are associated with protein misfolding and protein truncation-likely occurrences in the case of a foreign amino acid insertion during protein synthesis - and could conceivably trigger neurodegeneration.

Figure 2. Fluorescence and differential interference contrast microphotographs of lyophilized marine Nostoc sp.

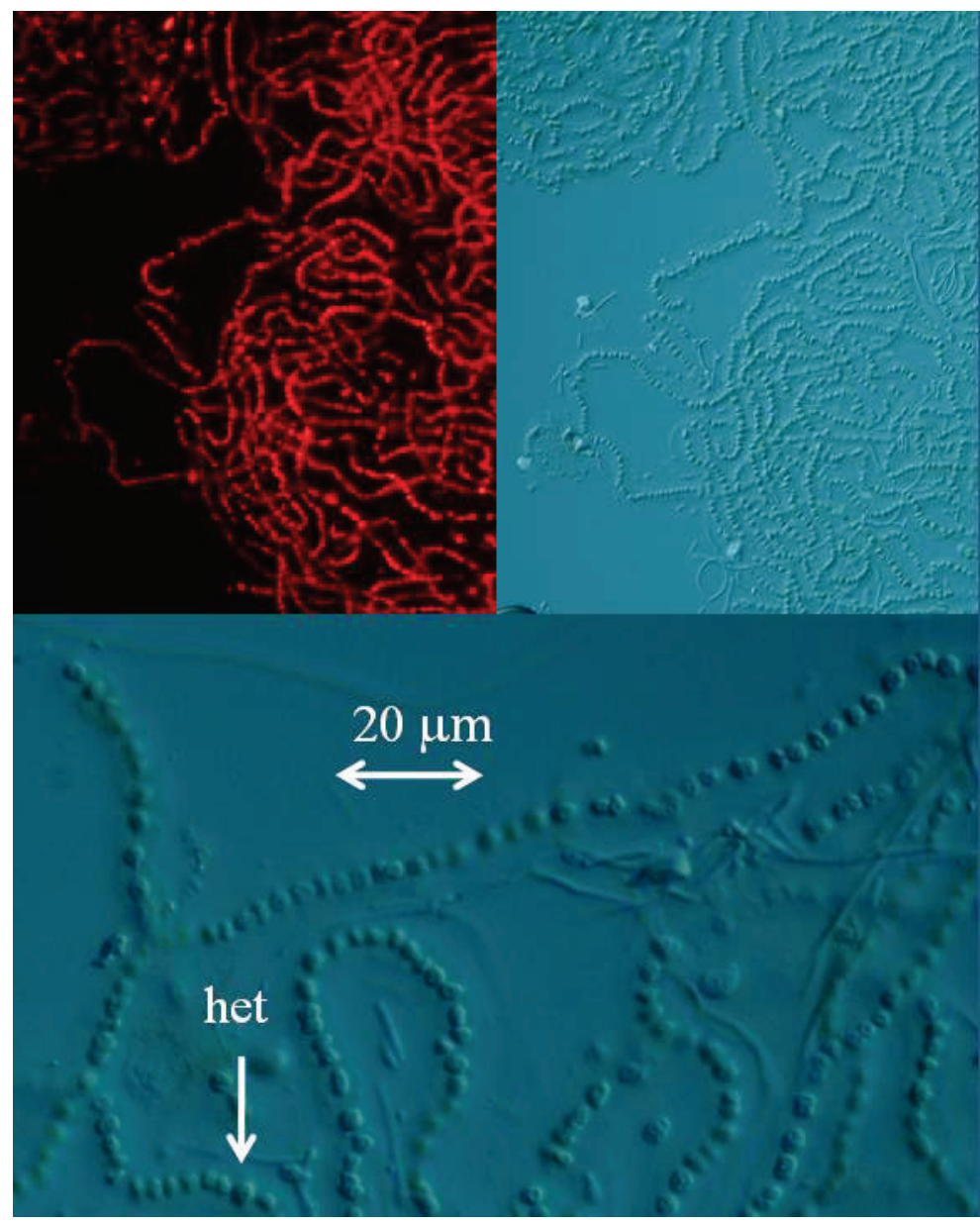


The incorporation of BMAA into protein was first demonstrated by Polsky, Nunn and Bell, who found BMAA in an extract removed from cycad seeds; acid hydrolysis of the extract released BMAA in greater amounts than found in the free fraction [20]. Subsequently, the insertion of BMAA into artificial peptides [21] further demonstrated the potential for protein-bound BMAA in natural systems. However, association of a non-protein amino acid like BMAA with proteins is not unusual, since there are many other cases of unusual amino acids being associated with cyanobacterial proteins [22]. For such studies, hydrochloric acid $(\mathrm{HCl})$ hydrolysis is by far the most commonly used method of releasing amino acids from proteins [23]. The conventional acidic hydrolysis uses $6 \mathrm{~N} \mathrm{HCl}$ for 18 to 24 hours in vacuo and provides high recovery of all protein-bound amino acids except tryptophan.

The detection and quantification of BMAA in a sample increases in difficulty as the concentration of BMAA decreases and the complexity of the physiological matrix increases. While it is relatively simple to detect the high concentration of BMAA in a cycad seed gametophyte or even a low concentration of synthetic BMAA standard with standard chromatographic techniques, detection of BMAA in low concentration in a complex physiological matrix (such as in a cyanobacterium, or a human brain sample) requires careful method development and validation. Single injection experiments, particularly those performed by investigators with little previous amino acid experience are unlikely to result in detection. Multiple techniques to confirm the presence of BMAA in a sample are preferred. To unequivocally demonstrate that a marine cyanobacterium, a laboratory strain of Nostoc sp. known as CMMED-01 (Figure 2), produces BMAA, we used five different techniques to assay it for the production of BMAA.

\section{Results and Discussion}

\section{2a. Fluorescence microscopic examination of CCMED-01}

Fluorescence microscopy of the lyophilized marine culture CCMED-01 confirmed that the sample was indeed cyanobacterial, while differential interference microscopy confirmed that it was a species of the genus Nostoc (Figure 2). The linear "pearls on a string" structure of Nostoc was visible with clear heterocysts, and the cyanobacterium fluoresced with excitation at $550 \mathrm{~nm}$ and emission at 590 $\mathrm{nm}$. However, since proportion of specific pigments may change during Nostoc lifecycles, emission wavelengths may also change [24].

\section{2b. Chromatographic and Spectrometric Determination of BMAA in CCMED-01}

All five of the different techniques we employed confirmed the presence of BMAA in lyophilized samples of the marine Nostoc strain, CMMED-01. High performance liquid chromatography with fluorescence detection (HPLC-FD) detected BMAA as a free amino acid (7 $\mu \mathrm{g} / \mathrm{g}$ ) in the marine Nostoc samples (Figure 3). The CCMED-01 peak for BMAA is consistent with the BMAA standard. Relative to the standard amino acids, BMAA elutes closest to methionine (MET). The HPLC analysis of free plus protein-bound BMAA, performed with different gradients, also detected the BMAA peak (Figure 4). In this analysis, $10 \mu \mathrm{g} / \mathrm{g}$ of BMAA was found in the Nostoc CMMED-01 sample. 
Figure 3. HPLC-FD chromatogram of free BMAA in marine Nostoc.

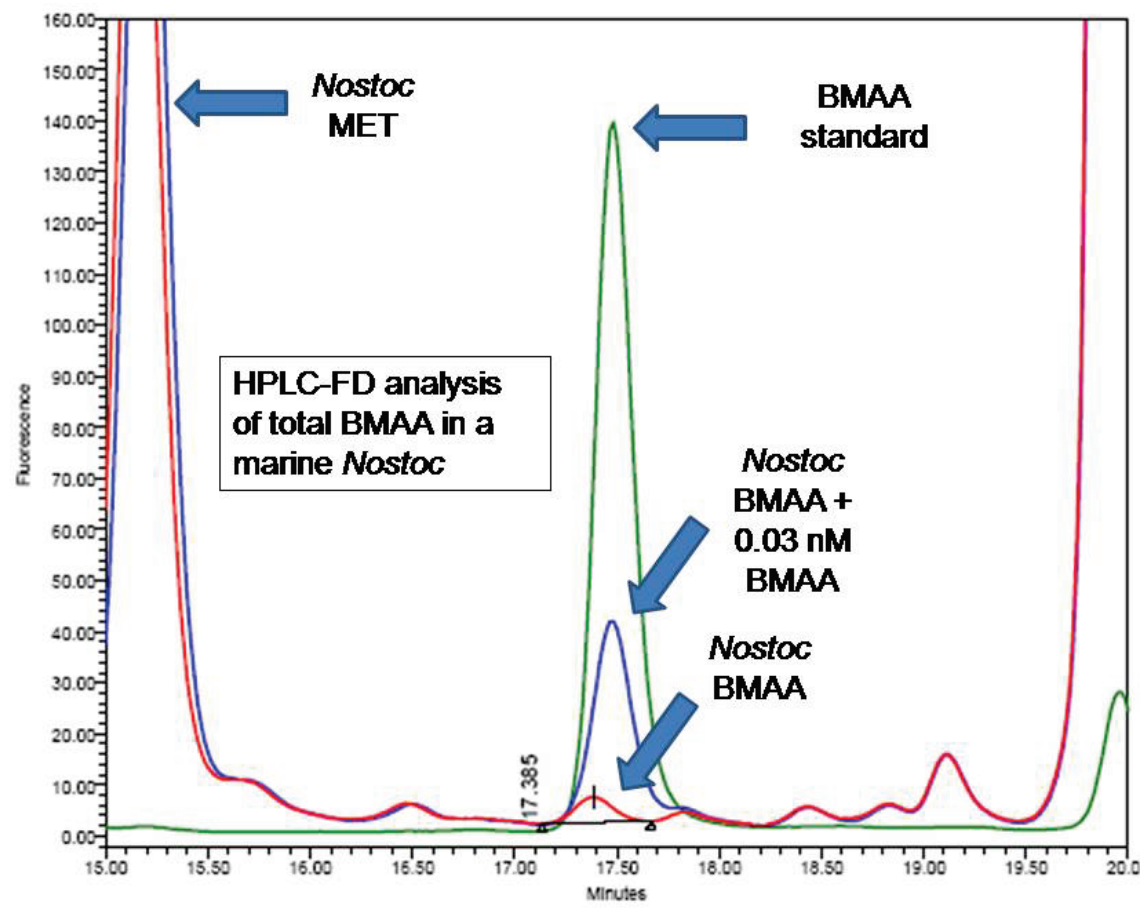

The sample spiked with 32 picomoles of BMAA elutes within the time range of the synthetic BMAA (Figure 4). Although the two different HPLC-FD analyses use different gradients, they were united by the use of a sodium acetate buffer and fluorescent detection.

Figure 4. HPLC-FD of total BMAA in a marine Nostoc.

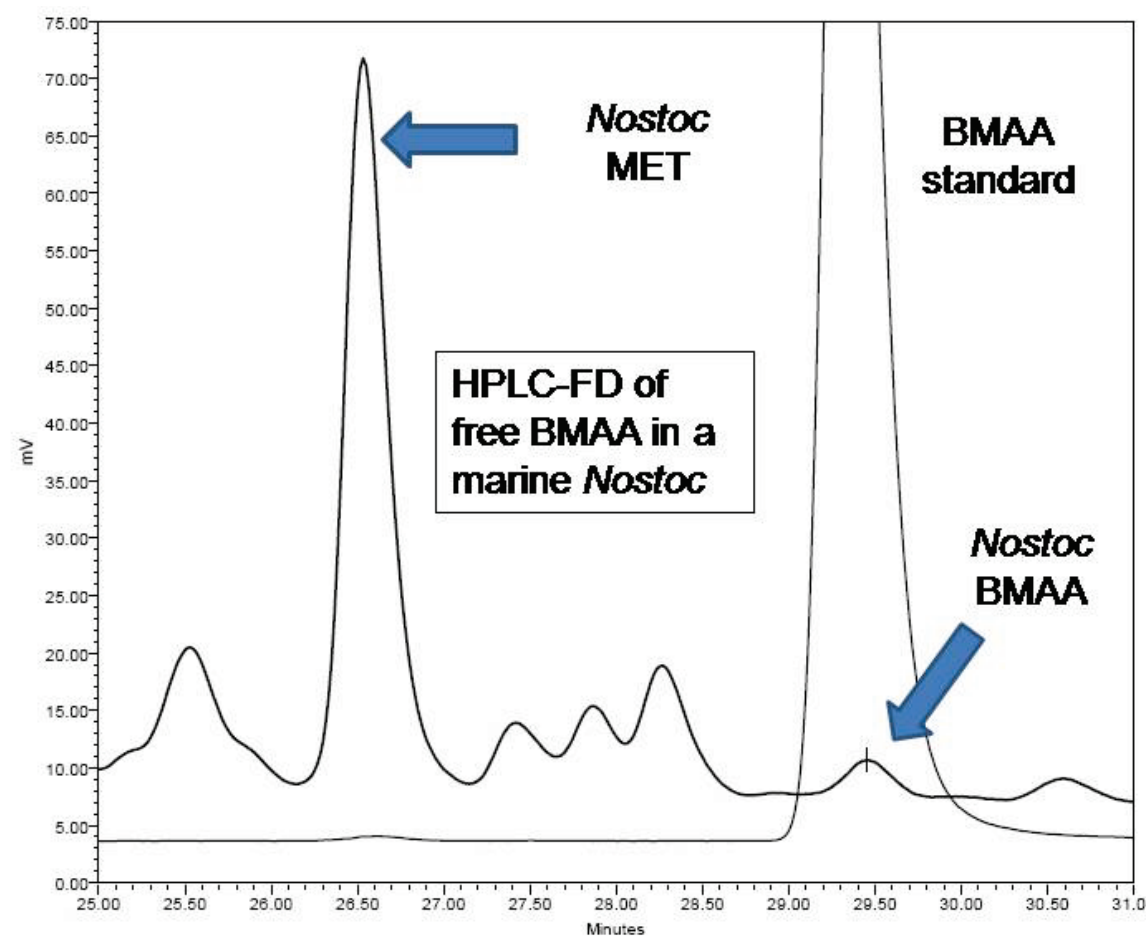

In contrast, during Ultra Performance Liquid Chromatography (UPLC), which operates at much higher pressure and uses a formic acid buffer instead of sodium acetate, BMAA elutes closest to 
lysine, and the sequence of amino acids is totally different. The UPLC method with UV detection determined the presence of BMAA $(25 \mu \mathrm{g} / \mathrm{g})$ in a CCMED-01 cyanobacterial sample (Figure 5).

Figure 5. BMAA elutes in a different position in UPLC than in HPLC.

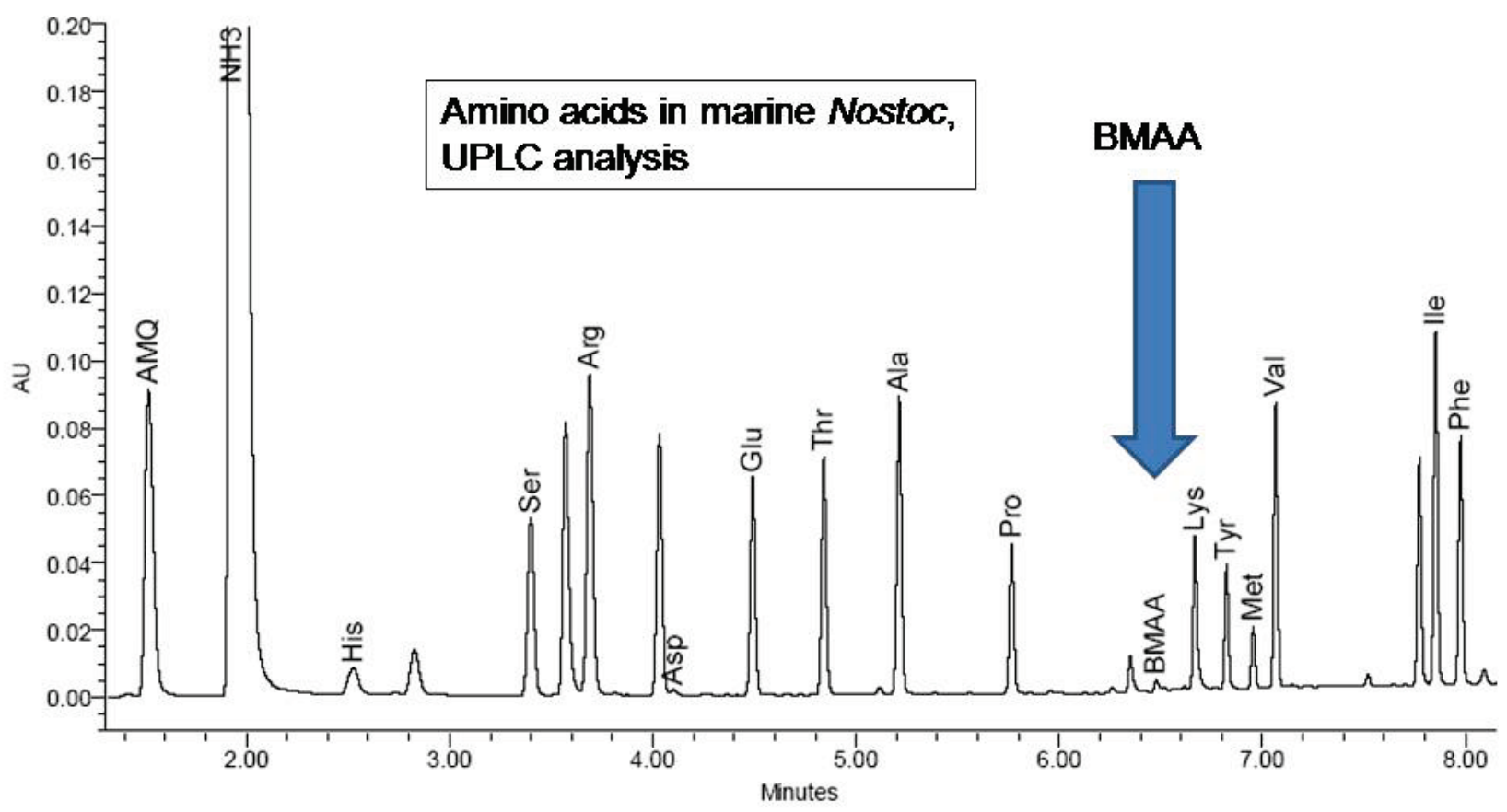

In both HPLC methods and the UPLC method, precolumn derivatization of the amino acids in the sample was performed using the fluorescent tag 6-aminoquinolyl- $N$-hydroxysuccinimidyl carbamate (AQC). AQC universally tags amino acids at primary and secondary nitrogens producing complex molecules that do not degrade during high pressure separation and are stable for a period of up to six months of normal storage [25]. Further advantages of the AQC reaction include the increased sensitivity over less modern techniques including phenylisothiocyanate (PITC), o-pthalaldehyde (OPA) and FMOC derivatizations, and increased efficiency of separation by reverse phase chromatography.

In contrast to the HPLC and UPLC techniques which use precolumn AQC derivatization of the cyanobacterial sample, BMAA was also detected with a Hitachi Amino Acid Analyzer (AAA) that uses postcolumn derivatization with ninhydrin (Figure 6). Amino acid analyzers are often used in hospital settings for analysis of amino acid contents of physiological fluids. In the AAA system, the non-protein amino acid BMAA elutes between ammonia and lysine. Once again, the sequence of amino acids coming off the column is totally different from the HPLC sequence and the UPLC sequence. Since BMAA, relative to other more common amino acids, elutes in a different position in the sequence than in HPLC and UPLC, with the use of such multiple techniques, the possibility of experimental error due to coelution of BMAA with another molecule can be minimized.

While the three different liquid chromatography techniques we employed (HPLC, UPLC, and Amino Acid Analyzer) depend on differential retention time of an analyte in a chromatographic column as compared to other molecules, mass spectrometry differentiates amino acids by their molecular weight. This combination of BMAA detection with HPLC or UPLC coupled with mass 
spectrometric verification of the BMAA peak reconfirms HPLC or UPLC detection of BMAA in a sample $[8,11,12,19]$.

Figure 6. BMAA appears in a different position with an amino acid analyzer than in HPLC or UPLC.

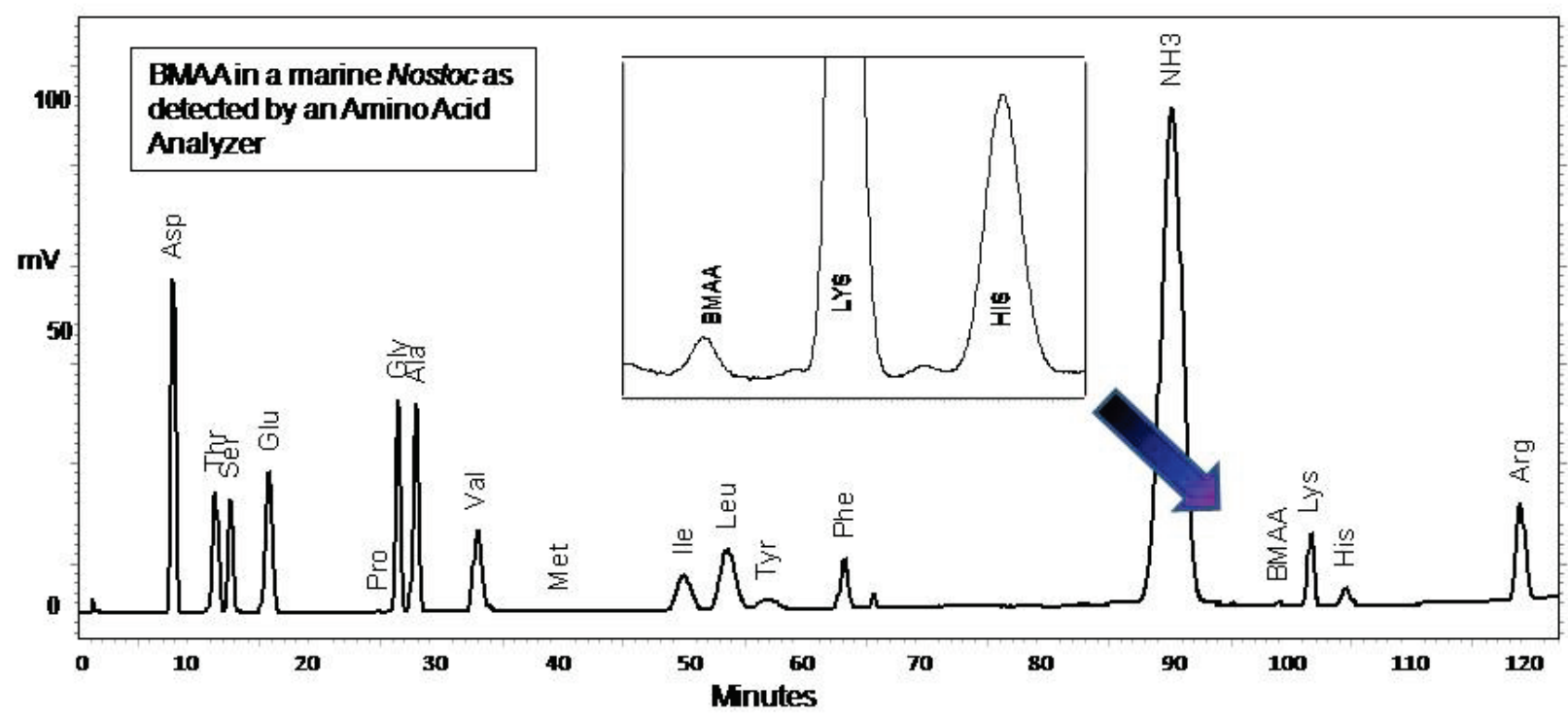

We used two different spectrometric techniques to verify the BMAA peak in the CCMED-01 marine Nostoc sp. samples. First, we used a Waters EMD-1000 single quadrupole mass spectrometer to determine the mass of the peak we identified as BMAA with the UPLC separation. Using a direct UPLC injection of the AQC-derivatized sample into a single quadrupole liquid chromatograph/ mass spectrometer (LC/MS), BMAA was clearly detected (Figure 7) with a mass of 459 [mw= BMAA (118) + two AQC molecules $(\mathrm{mw}=170)$ at the two nitrogen groups + one ion at the LC/MS electrospray interface].

Figure 7. An in-line UPLC/LCMS was used to verify the BMAA peak.

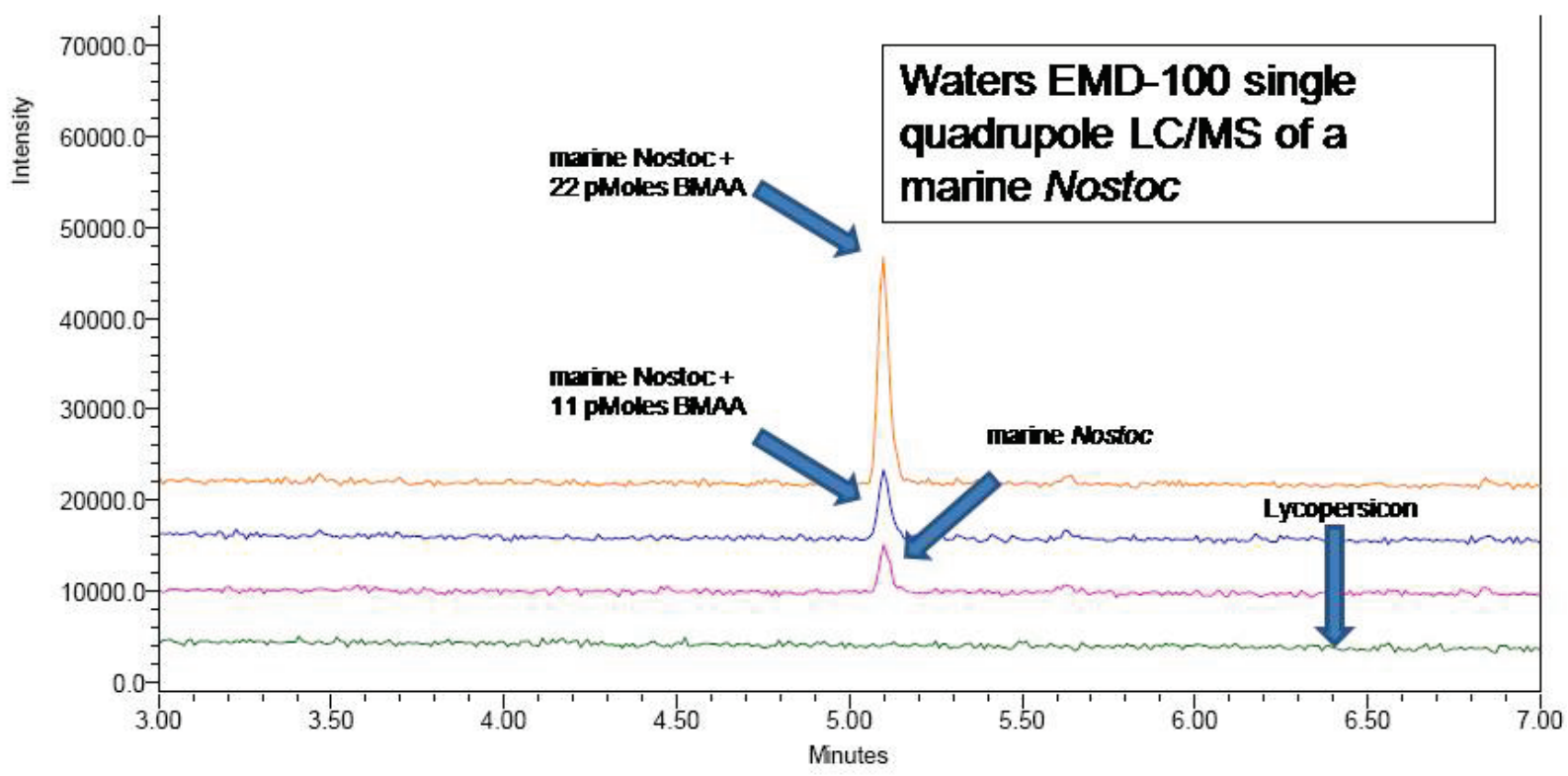


We also detected BMAA from an LC injection into a triple quadrupole LC/MS/MS. In this case, we compared the fragmentation pattern of BMAA in the second quadrupole to that of another amino acid, $L$-2,4-diamino- $n$-butyric acid, which has a molecular weight of 118.13 , equivalent to BMAA, but with a different molecular structure. Our triple quadrupole instrument is designed to detect low molecular weight molecules in a complex physiological matrix [26]. This instrument has four checks to determine that the test molecule is equivalent to the standard: (1) in the first quadrupole, the instrument excludes all ions except the specific single parent mass ( $459 \mathrm{mw}$ ) from entering the second quadrupole; (2) the retention time of the molecule after interaction with the column is unique; (3) the product ions detected in the third quadrupole must all be present following the collision-induced dissociation within the second quadrupole; and (4) the ratios of the three product ions (Figure 8) must match within $\pm 5 \%$ variation as compared with repetitive runs of the BMAA standard injected at a similar concentration. We used three aliquots from a CMMED-01 sample, and used 17 different runs of BMAA standard to estimate experimental variance.

Our Nostoc sp. sample met all four of these checks for the presence of BMAA: (1) in the first quadrupole, ions with a mass of 459 were present; (2) the retention time for the sample was 13.59 min. \pm 0.08 compared to $13.49 \mathrm{~min}$. \pm 0.11 for the BMAA standard; (3) the product ions with masses of 171,289 , and 119 were detected in the third quadrupole for both the sample and the BMAA standard; (4) the ratio of the three fragmentation product ions were similar for the sample and the BMAA standard (Figures 8,9 ). The ratios are normalized by the proportion of the largest daughter ion with a mass of 171 (A). The ratios of the product ion with mass of 289 (B) to the daughter ion with mass of 171 (A) for sample and standard were $25.3 \pm 0.97$ and $24.4 \pm 1.8$, respectively; while the ratios for product ions with mass of 119 (C) to the daughter ion with mass of 171 (A) were $11.9 \pm 0.69$ and 12.5 \pm 0.3 , respectively.

Figure 8. Product ions from collision-induced dissociation of double-derivatized BMAA in $\mathrm{LC} / \mathrm{MS} / \mathrm{MS}$.

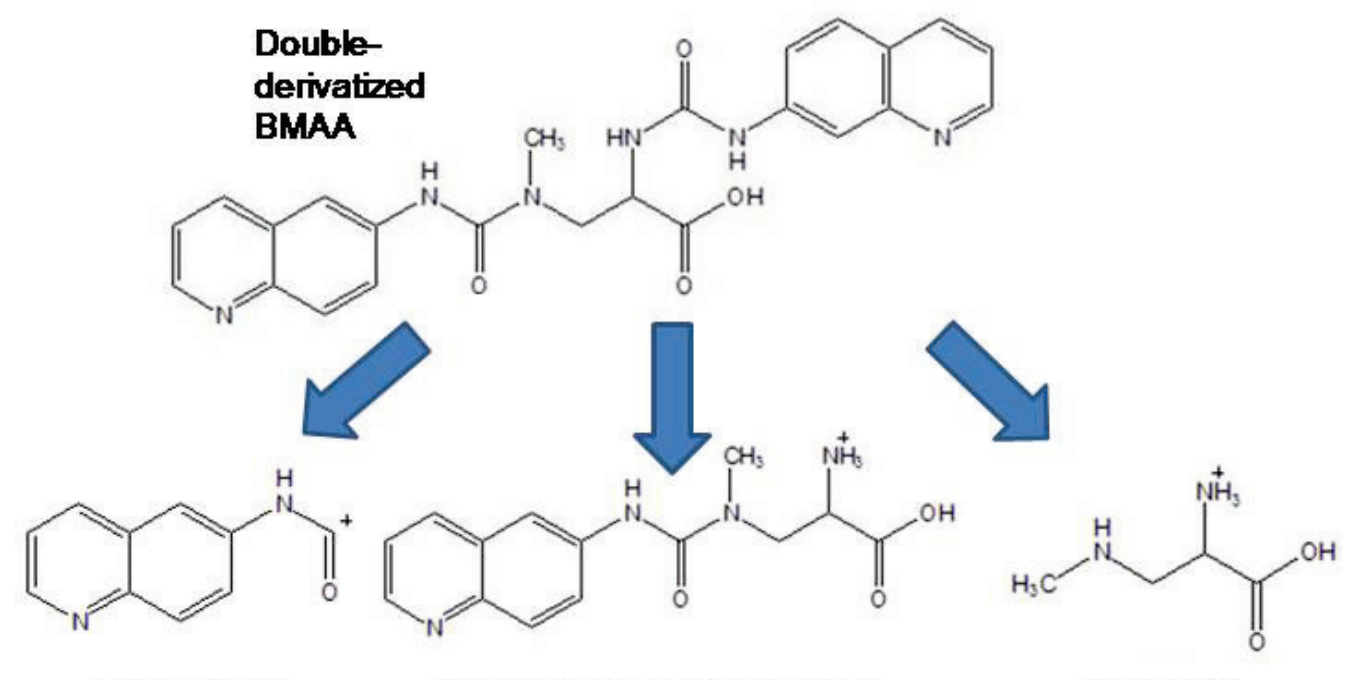

(A) AQC tag

(B) Single-derivatizedBMAA

(C) BMAA 
Figure 9. Triple quadrupole LC/MS/MS of BMAA in a marine Nostoc sp.

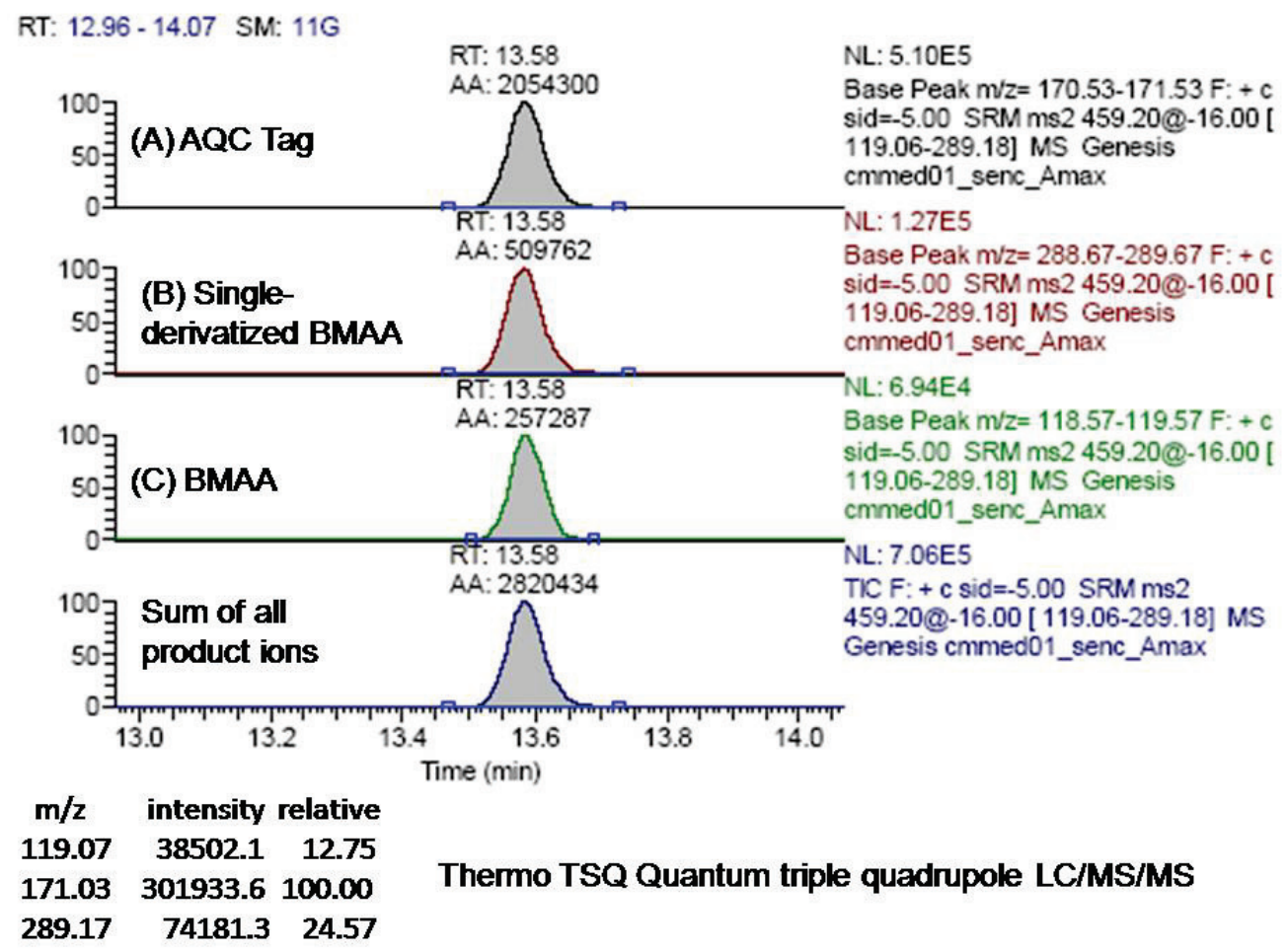

\section{Conclusions}

The use of three different HPLC techniques and two different LC/MS techniques conclusively demonstrates that the marine cyanobacterial species represented by Nostoc CCMED-001 produces the neurotoxic non-protein amino acid, $\beta$-methylamino- $L$-alanine. The precise fragmentation pattern and collision-induced dissociation ion ratios of the LC/MS/MS provide unequivocal evidence of BMAA in the sample. Although BMAA is present in the cyanobacterium, we detected some variation in concentration since the samples tested were taken at different times from the parent culture. Variation in concentration is not unexpected, since nitrogenase activity within marine cyanobacteria can vary dramatically within a single day as well as throughout the life cycle depending on the specific taxon, photon flux, and culture senescence [27-29]. Our study confirming through five different techniques the presence of BMAA in a marine Nostoc species supports the addition of BMAA to the list of phycotoxins produced by cyanobacteria [30].

Originally discovered in 1967 in cycad seeds from Guam [15, 16], BMAA for 45 years was believed to occur only in cycads. As such, the putative link of BMAA to the debilitating paralytic disease ALS/PDC suffered by the Chamorro people was believed to be related only to the Chamorro consumption of flour made from the seed gametophytes of Cycas micronesica Hill [15-20]. Claims that Chamorro processing procedures remove nearly all of the BMAA from cycad flour, combined with no clear etiological linkage of cycad consumption in the two other foci of ALS/PDC in West Papua and the Kii peninsula of Japan, led to BMAA being discounted as a possible cause of neurodegenerative illness among the Chamorro people [18]. Furthermore, there was no conceivable connection of BMAA to other forms of progressive neurodegenerative illness in the parts of the world where cycads do not occur. 
Interest in BMAA was rekindled, however, in 2002 when it was hypothesized that BMAA may accumulate within animals that eat cycads [32]. Experimental evidence for such bioaccumulation soon followed $[33,34]$. In 2003, it was discovered that BMAA is produced by cyanobacteria of the genus Nostoc which live as symbionts within specialized cycad roots [8]. In 2004 it was discovered that BMAA can be bound to proteins, including the proteins of cycad flour which had not been previously investigated [19]. Thus a new pictured emerged: BMAA was present within the traditional Chamorro diet from multiple sources in far higher concentrations than had previously been suspected [8, 19, 34]. In 2005, it was discovered that BMAA can be produced by diverse taxa of cyanobacteria [11]. It was thought that this broad pattern of cyanobacterial production of BMAA might provide a clue into why BMAA was found in brain tissues of patients with progressive neurodegenerative illness who lived far from Guam $[19,35]$.

Confirmation through five different techniques that BMAA is produced by the marine Nostoc species represented by the CCMED-01 samples increases our interest in finding out if this potent neurotoxin, which selectively targets motor neurons [13, 14], can be biomagnified within marine ecosystems. We await with interest the results of ongoing studies of BMAA biomagnification at the University of Hawaii, Stockholm University, Chiba University, and our Institute designed to test this possibility. It also would be interesting to know if marine (or even fresh-water) cyanobacteria play a role in human exposure to BMAA in the ALS/PDC focus in Kii, Japan. Furthermore, the recent finding that BMAA co-occurs with other cyanotoxins in contaminated water supplies raises the possibility that low-level human exposure to BMAA may occur in many parts of the world [12]. In contrast to ALS/PDC foci, such as Guam, where exposure to high levels of BMAA in traditional diets may constitute a broad threat to human health, exposures to low concentrations of BMAA in marine or freshwater ecosystems may trigger progressive neurodegenerative illness among genetically vulnerable individuals, potentially resulting in a new paradigm for sporadic motor neuron disease $[19,36]$. Until more is known about the possible link between BMAA and gene/environment interactions in progressive neurodegenerative illnesses, we again suggest [11] that it is now prudent to begin to assemble baseline data on the presence of BMAA in water supplies and human diets.

\section{Experimental}

\section{General}

The marine Nostoc sp. culture CMMED-01 was based on a sample originally collected on June 2, 2004 in Kaneohe Bay, on the island of Oahu in Hawaii by D. Hashimoto and identified by B. Anderson. This collection was cultured and maintained by R. Bidigare, G, Tien and colleagues at The Center for Marine Microbial Ecology and Diversity at the University of Hawaii, Manoa and sent to our laboratory by S. Christensen and A. Messner.

\section{4a. Fluorescence microscopy}

The lyophilized marine Nostoc sp. culture was reconstituted in water, and fresh mounted or mounted with Permount SP15-100 Toluene solution (Fisher Scientific, Fair Lawn, NJ) on microscope 
slides. The cyanobacteria were imaged with a Zeiss Axioplan 2 microscope. The cyanobacteria were examined with differential interference contrast and fluorescence microscopy with excitation at 550 $\mathrm{nm}$ and emission at $590 \mathrm{~nm}$ using a Chroma filter set (Chroma Technology, Rockingham, VT).

\section{4 b1. Fluorescence HPLC methods for analysis of free-BMAA}

Freeze-dried cyanobacterial samples were macerated in liquid nitrogen, weighed, hand macerated in trichloroacetic acid $(0.4 \mathrm{mg} / \mathrm{mL} 0.1 \mathrm{~N} \mathrm{TCA})$, vortexed, and extracted for $12 \mathrm{~h}$ at $4^{\circ} \mathrm{C}$. Samples were centrifuged and the supernatant decanted. The pellet was remacerated in TCA (50 $\mu \mathrm{L})$, vortexed, and re-extracted for $1 \mathrm{~h}$ at room temperature. Samples were centrifuged and the TCA supernatants pooled and filtered (0.22 $\mu \mathrm{m}$ Ultrafree-MC, Millipore) at 13,800 g for $5 \mathrm{~min}$ (Labnet Spectrafuge 16M). Free amino acid extracts were derivatized with 6-aminoquinolyl- $N$-hydroxysuccinimidyl carbamate (AQC Waters AccQTag reagent, PN WAT052880) following standardized, validated protocols: sample (20 $\mu \mathrm{L})$ was buffered with $0.5 \mathrm{M}$ borate $(80 \mu \mathrm{L})$ and derivatized with AQC $(20 \mu \mathrm{L})$ [9]. Sample batches for analysis included derivatized samples, blanks $[20 \mathrm{mM} \mathrm{HCl}(20 \mu \mathrm{L}$ with $0.5 \mathrm{M}$ borate $(80 \mu \mathrm{L})$ and derivatized with AQC $(20 \mu \mathrm{L})$ ], derivatized 17 amino acid standard complex (Pierce \#NCI0180, Rockford, IL) spiked with BMAA to assure adequate separation, derivatized BMAA standard for quantification, water blanks, and derivatized low-level spiked samples for peak identification and to check for a balanced reaction. BMAA was separated from other amino acids by reverse-phase elution (Waters Nova-Pak C18 column, 3.9 x $300 \mathrm{~mm}$ ) on a Waters 1525 binary HPLC pump and a Waters 717 Autosampler using a gradient method with $140 \mathrm{mM}$ sodium acetate, $5.6 \mathrm{mM}$ triethylamine, $\mathrm{pH} 5.2$ (Eluent $\mathrm{A}$ ), and $52 \%$ acetonitrile in water (Eluent B) at $37^{\circ} \mathrm{C}$, a flow rate of $1.0 \mathrm{~mL} / \mathrm{min}$, and a $10 \mu \mathrm{L}$ sample injection. The standard amino acid elution gradient was modified for BMAA separation on a 60 min gradient $(0.0 \mathrm{~min}=100 \% \mathrm{~A} ; 2 \mathrm{~min}=90 \% \mathrm{~A}$ curve $11 ; 5 \mathrm{~min}=84 \% \mathrm{~A}$ curve $11 ; 10 \mathrm{~min}=84$ $\%$ A curve $6 ; 18 \mathrm{~min}=75 \%$ A curve $6 ; 33 \mathrm{~min}=65 \%$ A curve $10 ; 35 \mathrm{~min}=40 \%$ A curve $6 ; 37.5 \mathrm{~min}$ $=100 \%$ B curve $6 ; 47 \mathrm{~min}=100 \%$ B curve $6 ; 50 \mathrm{~min}=100 \%$ A curve $6 ; 60 \mathrm{~min}=100 \%$ A curve 6 ). BMAA concentration was quantified by detection of the fluorescent tag (Waters 2475 Multi $\lambda$ Fluorescence Detector) with excitation at $250 \mathrm{~nm}$ and emission at $395 \mathrm{~nm}$ (Figure 2) and by comparison to an authenticated synthetic BMAA standard (P. Nunn, Univ. of Portsmouth, UK).

\section{4b2. Fluorescence HPLC methods for analysis of total BMAA}

CMMED-01 was hydrolyzed $(63 \mathrm{mg} / \mathrm{mL}$ wet weight) in $6 \mathrm{~N} \mathrm{HCl}(400 \mu \mathrm{L})$ for 16 hours at 110EC. The hydrolysate $(200 \mu \mathrm{L})$ was filtered at $13,800 \mathrm{~g}$ for $3 \mathrm{~min}(0.22 \mu \mathrm{m}$ Ultrafree-MC, Millipore). The residue was dried down using a speed vacuum (Thermo-Savant SC250DDA Speed Vac Plus, Waltham, MA) and resuspended in $20 \mathrm{mM} \mathrm{HCl}(100 \mu \mathrm{L})$. The sample was diluted 1:10 using $20 \mathrm{mM}$ $\mathrm{HCl}$ before derivatization with 6-aminoquinolyl- $N$-hydroxysuccinimidyl carbamate [sample $(20 \mu \mathrm{L})$ was buffered with $0.5 \mathrm{M}$ borate $(80 \mu \mathrm{L})$ and derivatized with AQC $(20 \mu \mathrm{L})]$. Sample batch included blanks [20 mM HCl $(20 \mu \mathrm{L})$ with $0.5 \mathrm{M}$ borate $(80 \mu \mathrm{L})$ and derivatized with AQC $(20 \mu \mathrm{L})$ ], derivatized 17 amino acid standard complex (Pierce \#NCI0180, Rockford, IL) with a BMAA spike to assure adequate separation, derivatized BMAA standard for quantification, HPLC grade water blanks, derivatized low-level spiked samples for peak identification and to check for a balanced reaction, a 
matrix blank of hydrolyzed, derivatized Lycopersicon esculentum Mill. (Solanaceae) for a negative control, a matrix blank of hydrolyzed, derivatized L. esculentum spiked with low-levels of BMAA and a blank of derivatized $L$-2,4-diamino- $n$-butyric acid which has a molecular weight of 118.13 , equivalent to BMAA but with a different structure.

BMAA was separated from other amino acids by reverse-phase elution (Waters Nova-Pak C18 column, $3.9 \times 300 \mathrm{~mm}$ ) on a Waters 1525 binary HPLC pump and a Waters 717 Autosampler using a gradient method with $140 \mathrm{mM}$ sodium acetate, $5.6 \mathrm{mM}$ triethylamine, $\mathrm{pH} 5.7$ (Eluent $\mathrm{A}$ ), and 52\% acetonitrile in water (Eluent $\mathrm{B}$ ) at $37^{\circ} \mathrm{C}$, a flow rate of $1.0 \mathrm{~mL} / \mathrm{min}$, and a $20 \mu \mathrm{L}$ sample injection. The standard amino acid elution gradient was modified for BMAA separation on a 30 min gradient $(0.0$ $\min =75 \% \mathrm{~A} ; 2.0 \mathrm{~min}=75 \%$ A curve $6 ; 17.0 \mathrm{~min}=63 \% \mathrm{~A}$ curve $7 ; 18.5 \mathrm{~min}=100 \% \mathrm{~B}$ curve $6 ; 23.5$ $\min =100 \%$ B curve $6 ; 25.0 \mathrm{~min}=75 \%$ A curve $6 ; 30.0 \mathrm{~min}=75 \%$ A curve 6 ). BMAA concentration was quantified by detection of the fluorescent tag (Waters 2475 Multi $\lambda$-Fluorescence Detector) with excitation at $250 \mathrm{~nm}$ and emission at $395 \mathrm{~nm}$ (fig. 3) and by comparison to an authenticated synthetic BMAA standard (P. Nunn).

\section{4c. UPLC-UV Methods for quantification of total BMAA in CMMED-01}

Methods for quantification of BMAA were adapted from previously validated High Performance Liquid Chromatography (HPLC) methods [11] which were transferred and optimized to Ultra Performance Liquid Chromatography (UPLC7). Waters Acquity UPLC methods for amino acid analysis with ultraviolet (UV) detection were used with a modified solvent gradient and validated in compliance with United States Pharmacopeia General Chapter 1225 [31]. Eluents were purchased from Waters (Eluent A: part \#186003838, Eluent B: part \# 186003839); composition is proprietary. Separation was by reverse phase over 9.5 minutes on a Waters AccQTag Ultra column (part\# $186003837,2.1 \times 100 \mathrm{~mm})$ at $55^{\circ} \mathrm{C}$ with a flow rate of $0.7 \mathrm{~mL} / \mathrm{min}(0.0 \mathrm{~min}=0.1 \% \mathrm{~B} ; 0.54 \mathrm{~min}=$ $0.1 \% \mathrm{~B}$ curve $6 ; 6.24 \mathrm{~min}=9.1 \% \mathrm{~B}$ curve $7 ; 7.74 \mathrm{~min}=21.2 \% \mathrm{~B}$ curve $6 ; 8.04 \mathrm{~min}=59.6 \% \mathrm{~B}$ curve $6 ; 8.73 \mathrm{~min}=0.1 \% \mathrm{~B}$ curve $6 ; 9.5 \mathrm{~min}=0.1 \% \mathrm{~B}$ curve 6 ).

Validation was completed using a BMAA standard (synthesized standard P. Nunn) derivatized with 6-aminoquinolyl- $N$-hydroxysuccinimidyl carbamate. Ruggedness was evaluated by calculating the precision of biweekly triplicate injections at one concentration over 32 weeks (RSD 3.6\%). Linearity was evaluated by plotting peak area as a function of analyte concentration based on 9 injections from each of 21 different preparations and regression analysis was performed: slope $=5589$; intercept $=-3198$; correlation coefficient $=0.9998$; residual sum of squares $=1291469639$. The limit of detection (LOD) and limit of quantification (LOQ) were determined as 0.1 pmol and $1.1 \mathrm{pmol}$ respectively, with a linear range to 539 pmol per injection. Accuracy (recovery $=98 \%$ ) was calculated by spiking negative control matrix, Lycopersicon esculentum, with known amounts of BMAA in triplicate at five concentrations. Precision was evaluated with two measures, repeatability and intermediate precision. Repeatability was assessed with triplicate injections at five concentrations on two consecutive days (RSD 1.2\%). Intermediate precision was calculated biweekly over 32 weeks with triplicate injections at three concentrations (RSD 3.9\%). Selectivity was verified with in-line LC/MS as noted below.

Methods for sample preparation were adapted from validated HPLC methods [11]. Twenty mg of 
freeze dried cells from cultured CMMED-01 were weighed in triplicate and hydrolyzed in $6 \mathrm{M} \mathrm{HCl}$ $(400 \mu \mathrm{L})$ at $110^{\circ} \mathrm{C}$ for 16 hours. Hydrolysate $(200 \mu \mathrm{L})$ was filtered with a $0.22 \mu \mathrm{m}$ centrifugal filter device (Millipore Ultrafree-MC), dried to completeness, then suspended in $20 \mathrm{mM} \mathrm{HCl}(100 \mu \mathrm{L})$ and diluted 1:10. Sample $(20 \mu \mathrm{L})$ was buffered with $0.5 \mathrm{M}$ borate $(80 \mu \mathrm{L})$ and derivatized with Waters AccQTag reagent $(20 \mu \mathrm{L}) ; 2 \mu \mathrm{L}$ were injected. BMAA in the cyanobacterial samples was quantified using the validated UPLC method above, with UV detection at $260 \mathrm{~nm}$. Sample batch included blanks [20 mM HCl $(20 \mu \mathrm{L})$ with $0.5 \mathrm{M}$ borate $(80 \mu \mathrm{L})$ and derivatized with AQC $(20 \mu \mathrm{L})$ ], derivatized 17 amino acid standard complex (Pierce \#NCI0180, Rockford, IL) spiked and unspiked with BMAA to assure adequate separation, derivatized BMAA standard for quantification, derivatized low-level spiked samples for peak identification and to check for a balanced reaction, a negative matrix blank of hyrdolyzed Homolanthus nutans Muell. Arg. (Euphorbiaceace), and a matrix blank of hydrolyzed $H$. nutans spiked with low-levels of BMAA. The presence of the non-protein amino acid BMAA as well as some of the 20 essential protein amino acids were determined by reference to synthetic BMAA and a multiple amino acid standard (Pierce \#NCI0180, Rockford, IL.; Figures 4, 5).

\section{4d. Amino Acid Analyzer methods for CCMED-01}

Freeze dried CMMED-01 Nostoc was hydrolyzed $(63 \mathrm{mg} / \mathrm{mL})$ in $6 \mathrm{~N} \mathrm{HCl}(400 \mathrm{~mL})$ for 16 hours at $110^{\circ} \mathrm{C}$. The hydrolysate $(200 \mu \mathrm{L})$ was filtered at $13,800 \mathrm{~g}$ for $3 \mathrm{~min}(0.22 \mu \mathrm{m}$ Ultrafree-MC, Millipore). The residue was dried down using a speed vacuum (Thermo-Savant SC250DDA Speed Vac Plus, Waltham, MA) and resuspended in $20 \mathrm{mM} \mathrm{HCL}(100 \mu \mathrm{L})$. The sample was diluted 1:10 using $20 \mathrm{mM} \mathrm{HCl}$. Underivatized sample $(20 \mu \mathrm{L})$ was injected into a Hitachi Amino Acid Analyzer L8900 equipped with a Hitachi Reaction column (PN 855-3533) at $135^{\circ} \mathrm{C}$, a high speed physiological fluid analysis analytical column Li-form resin \#2622SC 6 mm ID x 40 L 060928C (PN855-4515), precolumn (PN855-3643), guard column \#2619 4 mm ID x 5 L 2007.07.19 070639 (PN855-5268), and AmmoniaFilter column (Ion exchange 4.6 x 40 Column \#2650L, PN 855-3523). Hitachi pre-made buffers were used as follows: (B1) PF-1/AN0-8711, (B2) PF-2 /AN0-8712, (B3) PF-3/An0-8713, (B4) PF-4/An0-8714, (B5) 5\% methanol, (B6) PF-RG/An0-8715, (R1) ninhydrin solution, (R2) ninhydrinbuffer of lithium acetate dihydrate, (R3) 5\% ethanol. Separation was made with a flow rate for pump 1 of $0.53 \mathrm{~mL} / \mathrm{min}$ and $0.45 \mathrm{~mL} / \mathrm{min}$ for pump 2 and a $152 \mathrm{~min}$ gradient elution $(0.0 \mathrm{~min}=100 \% \mathrm{~B} 1$, separation column and guard column temp $35^{\circ} \mathrm{C}, 50 \% \mathrm{R} 1,50 \% \mathrm{R} 2 ; 1.5 \mathrm{~min}=$ column $32^{\circ} \mathrm{C} ; 15.6 \mathrm{~min}$ $=81 \% \mathrm{~B} 1,19 \% \mathrm{~B} 2$, column $57^{\circ} \mathrm{C} ; 36 \mathrm{~min}=60^{\circ} \mathrm{C} ; 45 \mathrm{~min}=32^{\circ} \mathrm{C} ; 57 \mathrm{~min}=70^{\circ} \mathrm{C} ; 68 \mathrm{~min}=15 \% \mathrm{~B} 1$, $75 \% \mathrm{~B} 2,10 \% \mathrm{~B} 3 ; 69 \mathrm{~min}=58^{\circ} \mathrm{C} ; 76.1 \mathrm{~min}=60 \% \mathrm{~B} 2,40 \% \mathrm{~B} 3 ; 89 \mathrm{~min}=65^{\circ} \mathrm{C} ; 95 \mathrm{~min}=20 \% \mathrm{~B} 2$, $80 \% \mathrm{~B} 4 ; 98.1 \mathrm{~min}=25 \% \mathrm{~B} 2,75 \% \mathrm{~B} 4 ; 112.1 \mathrm{~min}=100 \% \mathrm{~B} 4 ; 125 \mathrm{~min}=70^{\circ} \mathrm{C} ; 125.1 \mathrm{~min}=100 \% \mathrm{R} 3$; $\left.129.1 \mathrm{~min}=100 \% \mathrm{~B} 6 ; 132.1=100 \% \mathrm{~B} 1 ; 137.1 \mathrm{~min}=50 \% \mathrm{R} 1,50 \% \mathrm{R} 2,35^{\circ} \mathrm{C}\right)$. The presence of BMAA was verified by reference to an authenticated synthetic standard (P. Nunn), and a multiple amino acid standard (Pierce \#NCI0180, Rockford, IL, fig. 6). Sample batches included the following underivatized samples: amino acid standards with and without BMAA spikes, BMAA, L-2,4-diamino$n$-butyric acid, which has a molecular weight of 118.13 equivalent to BMAA, hydrolyzed Lycopersicon esculentum, o-methyl-L-tyrosine, $L$-o-methylthreonine, $s$-methyl- $L$-cysteine, $n$ - $\varepsilon$ methyllysine $\mathrm{HCl}, L$-2,3,diaminoproprionic acid $\mathrm{HCl}, N^{t}$-methyl- $L$-histidine, methylamine $\mathrm{HcC}, 3$ methyl- $L$-histidine, $N^{G}$-methyl-l-arginine and amino acid standard physiological basic A6282 (Sigma). 
4e. LC/MS methods for verification of presence of BMAA in CMMED-01

A CMMED-01 Nostoc sample prepared as in $2 \mathrm{a}$ was injected $(5 \mu \mathrm{L})$ into a Waters UPLC on a Waters AccQTag Ultra column (part\# 186003837, 2.1x100 mm) at $55^{\circ} \mathrm{C}$ with a flow rate of 0.7 $\mathrm{mL} / \mathrm{min}$, using the UPLC method previously noted. A post-column split of the flow delivered a flow rate of $0.3 \mathrm{~mL} / \mathrm{min}$ to a Waters EMD 1000 single quadrupole mass spectrometer. Nitrogen gas was purified to $99.2 \%$ using a NitroFlow nitrogen generator (Parker Balston, Haverfill, MA) and supplied to the electrospray ionization interface at 116 psi with desolvation at $500 \mathrm{~L} / \mathrm{hr}$. Positive ion mode was used to detect BMAA derivatized with 6-aminoquinolyl- $N$-hydroxysuccinimidyl carbamate (AQC) (Waters AccQTag reagent, part \# WAT052880), using single ion monitoring at 459.20 Daltons with a span of 0.3 Daltons and a dwell time of 0.5 seconds. The source temperature and desolvation temperature were $130^{\circ} \mathrm{C}$ and $300^{\circ} \mathrm{C}$ respectively. Voltages were as follows: capillary $3.05 \mathrm{kV}$, cone $27 \mathrm{~V}$, extractor $1 \mathrm{~V}$, RF lens $0.4 \mathrm{~V}$. LC/MS verification of the UPLC peak (Figure 5) was obtained (Figure 6), as were LC/MS verifications of AQC derivatized CMMED-01 samples spiked with 11 picomoles and 22 picomoles BMAA respectively (Figure 7). Sample batch included blanks [20 mM $\mathrm{HCl}(20 \mu \mathrm{L})$ with $0.5 \mathrm{M}$ borate $(80 \mu \mathrm{L})$ and derivatized with AQC $(20 \mu \mathrm{L})]$, derivatized 17 amino acid standard complex (Pierce \#NCI0180, Rockford, IL) spiked with BMAA to assure adequate separation, derivatized BMAA standard for quantification, and derivatized low-level spiked samples for peak identification and to check for a balanced reaction and a negative matrix blank of hyrdolyzed Lycopersicon esculentum Mill. (Solanaceae), a matrix blank of hydrolyzed L. esculentum spiked with low-levels of BMAA, and a blank of $L$-2,4-diamino- $n$-butyric acid which has a molecular weight of 118.13 equivalent to BMAA but with a different structure.

\section{4f. Triple Quadrupole LC/MS/MS}

Identification of a BMAA peak in a marine Nostoc CMMED-001 sample was verified by liquid chromatography/mass spectroscopy/mass spectroscopy (LC/MS/MS) using product ion mode in a triple quadrupole system. The freeze-dried cyanobacteria sample was hydrolyzed for 18 hours in $6 \mathrm{~N}$ $\mathrm{HCl}$ at $110^{\circ} \mathrm{C}$ and then dried to remove $\mathrm{HCl}$ in a Thermo-Savant SC250DDA Speed Vac Plus (Waltham, MA). The sample was reconstituted in dilute $\mathrm{HCl}(20 \mathrm{mM})$ and derivatized with AQC, which increased the molecular weight of the BMAA analyte from 118 to 458 . To increase the quantity of analyte injected into the LC/MS/MS, the BMAA peak was collected three times from a Waters 1525 binary HPLC pump and a Waters 717 Autosampler, with separation through a Waters $3.9 \times 300 \mathrm{~mm}$ Nova-Pak C18, $4 \mu \mathrm{m}$ column (Lot No.: 11143603410254 ) at $37^{\circ} \mathrm{C}$. Individual compounds were eluted from the column with a gradient elution of $140 \mathrm{mM}$ sodium acetate buffer, $5.6 \mathrm{mM}$ triethylamine, $\mathrm{pH}$ 5.7 (mobile phase A) and 52\% acetonitrile (mobile phase B) with a flow rate of $1.0 \mathrm{~mL} / \mathrm{min}$. The collected peaks were dried to reduce the volume in a Thermo-Savant SC250DDA Speed Vac Plus with a Savant refrigerator trap RVT 4104. The first collected peak was then reconstituted in HPLC grade water $(50 \mathrm{~mL})$, heated to $55^{\circ} \mathrm{C}$, vortexed, and then added to the second and third peak iteratively which were likewise heated and vortexed in a similar fashion. The concentrated filtrate was injected into a triple quadrupole system (Thermo model TSQ Quantum Discovery Max, San Jose, CA). Separation was achieved by liquid chromatography (Thermo model Surveyor LC, San Jose, CA) utilizing a 
Thermo Hypersil GOLD $100 \times 2.1 \mathrm{~mm}, 3 \mu \mathrm{m}$ column at $0.28 \mathrm{~mL} / \mathrm{min}, 0.1 \%$ formic acid in water (Eluent A), $0.1 \%$ formic acid in acetonitrile (Eluent $\mathrm{B})$ gradient elution $(0.0 \mathrm{~min}=100 \% \mathrm{~A} ; 2 \mathrm{~min}=$ $100 \% \mathrm{~A} ; 16 \mathrm{~min}=80 \% \mathrm{~A} ; 20 \mathrm{~min}=2 \% \mathrm{~A} ; 22 \mathrm{~min}=2 \% \mathrm{~A} ; 24 \min =81 \% \mathrm{~B} ; 26 \min =81 \% \mathrm{~A} ; 27$ $\min =100 \% A ; 31 \mathrm{~min}=100 \% \mathrm{~A}$ ). Nitrogen gas was supplied to the H-ESI probe (heated electrospray ionization) with a nebulizing pressure of $25 \mathrm{psi}$ and a vaporizing temperature of $300^{\circ} \mathrm{C}$. The mass spectrometer was operated under the following conditions: the capillary temperature was set at $280^{\circ} \mathrm{C}$, capillary offset of 35 , tube lens offset of 94 , source collision energy of 5 , and multiplier voltage of 1194. The second quadrupole was pressurized to 1.5 mTorr with 100\% Argon.

The derivatized molecule after ionization (MW 459) via HESI was selected as the precursor ion for analysis. Collision induced dissociation (CID) was achieved in the second quadrupole using the following parameters: $459 \rightarrow 119$ CE $19 ; 459 \rightarrow 171 \mathrm{CE} \mathrm{32}$; and $459 \rightarrow 289 \mathrm{CE} 16$. The resultant three product ions of the derivatized BMAA (MW 119, 289, 171) were scanned by the third quadrupole, subsequently detected, and their relative abundances quantified. The ratios of these three product ions were compared to the ratios of the product ions created by injection of AQC-derivatized ultra pure, triple crystallized BMAA standard (Peter Nunn) into the mass spectrometer under the same conditions (Figure 9). Sample batch included blanks $(20 \mu \mathrm{L}$ of $20 \mathrm{mM} \mathrm{HCl}$ with $80 \mu \mathrm{L} 0.5 \mathrm{M}$ borate and derivatized with $20 \mu \mathrm{L}$ AQC), derivatized 17 amino acid standard complex (Pierce \#NCI0180, Rockford, IL) to assure adequate separation, derivatized BMAA standard for quantification, HPLC grade water blanks, derivatized norleucine blanks, and a blank of $L$-2,4-diamino- $n$-butyric acid which has a molecular weight of 118.13 , equivalent to BMAA but with a different structure, retention time, and product ions.

\section{Acknowledgements}

These studies were funded by grants from the H.K.L. Castle Foundation, the Margaret Q. Landenberger Foundation, and the Wallace H. Coulter Foundation. We thank W. Bradley, G. Codd, J. Metcalf and two anonymous reviewers for helpful comments and criticisms; L. Atherton, C. Childs, I. Cumming, P. and H. Henry, K. Farkas, and P. Egan for laboratory equipment; and R. Bidigare, S. Christensen and A. Messner at the Center for Marine Microbial Ecology and Diversity at the University of Hawaii, Manoa for several CMMED-001 Nostoc samples taken at different times.

\section{References}

1. Dow, C. S.; Swoboda, U. K. Cyanotoxins. In Ecology of Cyanobacteria; Whitton B. A.; Potts, M., Eds; Kluwer Academic Press: Dordrecht, The Netherlands. 2000; pp. 613-632.

2. Kuiper-Goodman, T; Falconer, I.; Fitzgerald, J. Human health impacts. In Toxic Cyanobacteria in Water; Chorus, I.; Bartram, J., Eds.; E \& F. N. Spon: London, 1999; pp. 113-153.

3. Sivonen, K.; Jones, G. Cyanobacterial toxins In Toxic Cyanobacteria in Water; Chorus, I.; Bartram, J., Eds.; E \& F. N. Spon: London, 1993; pp. 41-111.

4. Jochimsen, E. M.; Carmichael, W. W.; An, J.; Cardo, D. M.; Cookson, S. T.; Holmes, C. E. M.; Antunes, B.; de Melo Filho, D. A.; Lyra, T. M.; Barreto, V. S. T.; Azevedo, S. M. O.; Jarvis, W. R. Liver failure and death after exposure to microcystins at a hemodialysis center in Brazil. $N$. 
Engl. J. Med. 1998, 338, 873-878.

5. Pouria, S.; de Andrade, A.; Barbosa, J.; Cavalcanti, R. L.; Barreto, V. T. S.; Ward, C. J.; Preiser, W.; Poon, G. K.; Neild, G. H.; Codd, G. A. Fatal microcystin intoxication in haemodialysis unit in Caruaru, Brazil. Lancet 1998, 352, 21-26.

6. Carmichael, W. W. The toxins of cyanobacteria. Sci. Am. 1994, 270, 78-86.

7. Codd, G. A.; Bell, S. G.; Kaya, K.; Ward, C. J.; Beattie, K. A.; Metcalf, J. S. Cyanobacterial toxins, exposure routes and human health. Eur. J. Phycol. 1999, 34, 405-415.

8. Cox, P. A.; Banack, S. A.; Murch, S. J. Biomagnification of cyanobacterial neurotoxins and neurodegenerative disease among the Chamorro people of Guam. Proc. Natl. Acad. Sci. USA. 2003, 100, 13380-13383.

9. Banack, S. A.; Cox, P. A. Distribution of the neurotoxic non-protein amino acid BMAA in Cycas micronesica Hill. Bot. J. Linnean Soc. 2003, 143, 165-168.

10. Rippka, R.; Deruelles, J. B.; Waterbury, J. B.; Herdman, M.; Stanier, R. Y. Generic assignments, strain histories and properties of pure cultures of cyanobacteria. J. Gen. Microbiol. 1979, 111, $1-61$.

11. Cox, P. A.; Banack, S. A.; Murch, S. J.; Rasmussen, U.; Tien, G.; Bidigare, R. R.; Metcalf, J. S.; Morrison, L. F.; Codd, G. A.; Bergman, B. Diverse taxa of cyanobacteria produce

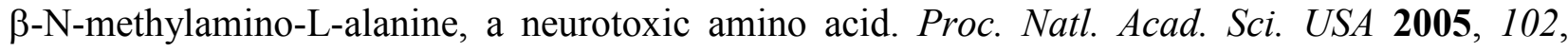
5074-5078.

12. Metcalf, J. S.; Banack, S. A.; Lindsay, J.; Morrison L. F.; Cox, P. A.; Codd, G. A. Co-occurrence of $\beta$-N-methylamino-L-alanine, a neurotoxic amino acid with other cyanobacterial toxins in British waterbodies, 1990-2004. Env. Microbiol. (in press).

13. Lobner, D.; Piana, P.M.T.; Salous, A.K.; Peoples, R.W. $\beta$-N-methylamino-L-alanine enhances neurotoxicity through multiple mechanisms. Neurobiol. Diseases. 2007, 25, 360-366.

14. Rao, S. D.; Banack, S. A.; Cox, P. A.; Weiss, J. H. BMAA selectively injures motor neurons via AMPA/kainite receptor activation. Exp. Neurol. 2006, 201, 244-252.

15. Vega, A.; Bell, E. A. $\alpha$-amino- $\beta$-methylaminopropionic acid, a new amino acid from seeds of Cycas circinalis. Phytochemistry 1967, 6, 759-762.

16. Vega, A.; Bell, E. A.; Nunn, P.B. The preparation of L- and D- $\alpha$-amino- $\beta$ -methylaminopropionic acid and the identification of the compound isolated from Cycas circinalis as the L-isomer. Phytochemistry 1968, 7, 1885-1887.

17. Spencer, P. S.; Kisby, G. E.; Ludolph, A. C. Slow toxins, biological markers, and long-latency neurodegenerative disease in the western Pacific region. Neurology 1991, 41, 62-66.

18. Ince, P. G.; Codd, G. A. Return of the cycad hypothesis - does the amyotrophic lateral sclerosis/parkinsonism dementia complex (ALS/PDC) of Guam have new implications for global health? Neuropathol. Appl. Neurobiol. 2005, 31, 345-353.

19. Murch, S. J.; Cox, P. A.; Banack, S. A. A mechanism for the slow release of biomagnified cyanobacterial neurotoxins and neurodegenerative disease in Guam. Proc. Natl. Acad. Sci. USA 2004, 101, 12228-12231.

20. Polsky, F. I.; Nunn, P. B.; Bell, E. A. Distribution and toxicity of $\alpha$-amino- $\beta$ methylaminopropionic acid. Fed. Proc. 1972, 31, 1473-1475.

21. Seebach, D.; Studer, A.; Pfammatter, E.; Widmer, H. Synthesis of tri-, penta-, and heptapeptides 
containing an (R)-2-Alkyl-2-amino-3-(methylamino)-propionic acid residue in the central position. Helv. Chim. Acta 1994, 77, 2035-2050.

22. Neilan, B. A.; Dittmann, E.; Rouhiainen, L.; Bass, R. A.; Schaub, V.; Sivonen, K.; Börner, T. Nonribosomal peptide synthesis and toxigenicity of cyanobacteria. J. Bacteriol. 1999, 181, 4089-4097.

23. Fountoulakis, M.; Lahm, H-W. Hydrolysis and amino acid composition analysis of proteins. $J$. Chrom. A. 1998, 826, 109-134.

24. Wolf, E.; Schüssler, A. Phycobuliprotein fluorescence of Nostoc punctiforme changes during the life cycle and chromatic adaptation: characterization by spectral confocal laser scanning microscopy and spectral unmixing. Plant Cell Environ. 2005, 28, 480-491.

25. Cohen, S. A.; Michaud, D. P. Synthesis of a fluorescent derivatizing reagent, 6-aminoquinolyl-Nhydroxysate amino acids via high-performance liquid chromatography. Anal. Biochem. 1993, 211, 279-287.

26. Domon, B.; Aebersold, R. Mass spectrometry and protein analysis. Science 2006, 312, 212 - 217.

27. Jones, K. Diurnal nitrogen fixation in tropical marine cyanobacteria : a comparison between adjacent communities of non-heterocystous Lyngbya sp. and heterocystous Calothrix sp. Br. Phycol. J. 1992, 27, 107-118.

28. Evans, A. M.; Gallon, J. R.; Jones, A.; Stall, M; Stal L. J.; Villbrandt, M.; Walton, T. J. Nitrogen fixation by Baltic cyanobacteria is adapted to the prevailing photon flux density. New Phytol. 2000, 147, 285-297.

29. Fredriksson, C.; Bergman, B. Nitrogenase quantity varies diurnally in a subset of cells within colonies of the non-heterocystous cyanobacteria Trichodesmium spp. Microbiology 1995, 141, 2471-2478.

30. Mazur-Marzec, H. Characterization of phycotoxins produced by cyanobacteria. Oceanol. Hydrobiol. Stud. 2006, 35, 85-109.

31. United States Pharmacopeia. The United States Pharmacopeia. 27th ed., and The National Formulary, 22nd ed.; United States Pharmacopeial Convention, Inc.: Rockville, MD, 2004.

32. Cox, P. A.; Sacks, O. W. Cycad neurotoxins, consumption of flying foxes, and ALS/PDC disease in Guam. Neurology 2002, 59, 1664-1665.

33. Banack, S. A.; Cox, P. A. Biomagnification of cycad neurotoxins in flying foxes: implications for ALS-PDC in Guam. Neurology 2003, 6, 387-389.

34. Banack, S. A.; Murch, S. J.; Cox, P. A. Neurotoxic flying foxes as dietary items for the Chamorro people, Marianas Islands. J. Ethnopharm. 2006, 106, 97-104.

35. Murch, S. J.; Cox, P. A.; Banack, S. A.; Steele, J. C.; Sacks, O. W. Occurrence of b-methylamino1-alanine (BMAA) in ALS/PDC patients from Guam. Acta Neurol. Scan. 2004, 110, 267-269.

36. Papapetropoulos, S. Is there a role for naturally occurring cyanobacterial toxins in neurodegeneration? The beta-N-methylamino-l-alanine (BMAA) paradigm. Neurochem. Int. 2007, 50, 998-1003.

Sample Availability: Contact the authors.

(C) 2007 by MDPI (http://www.mdpi.org). Reproduction is permitted for noncommercial purposes. 